\title{
PEMBELAJARAN MEMBACA SUKA UANG UNTUK PESERTA DIDIK TUNAGRAHITA KELAS DUA
}

\author{
Sri Suprapti \\ SLB Manunggal Slawi \\ srisupraptislawi@gmail.com
}

\begin{abstract}
Abstrak
Tujuan penelitian ini memperbaiki dan meningkatkan hasil belajar membaca peserta didik tunagrahita kelas dua semester satu di SLB Manunggal Slawi melalui pembelajaran membaca suka uang. Sekitar $80 \%$ peserta didik tunagrahita kelas dua di SLB Manunggal Slawi belum dapat membaca, bahkan belum mengenal huruf. Hal ini disebabkan oleh banyak faktor, diantaranya : sulit konsentrasi, rendahnya motivasi, dan IQ peserta didik yang rendah. Dari faktor penyebab tersebut, metode suku kata berulang, sebagai metode membaca yang diadaptasi untuk peserta didik dengan hambatan intelektual dimana pembelajaran diawali kegiatan ice breaker yang menyenangkan, materi yang mudah, diharapkan akan memotivasi, memunculkan rasa percaya diri dan peserta didik akan menyukai belajar, sehingga hasil pembelajaran meningkat. Penelitian ini merupakan penelitian tindakan kelas (classroom action research). Subyek penelitiannya adalah peserta didik tunagrahita (hambatan intelektual / intelectual disability) kelas dua Semester dua SLB Manunggal Slawi berjumlah 10 orang. PTK ini dilakukan dalam 2 siklus, dimana setiap siklus terdiri dari 3 pertemuan. Dalam 1 pertemuan ada 4 tahapan yaitu : perencanaan, pelaksanaan, observasi dan refleksi. Penelitian ini menggunakan metode kualitatif, dengan teknik pengumpulan data melalui observasi dan tes penguasaan membaca, yang dianalisis menggunakan analisis deskriptif komparatif. Berdasarkan hasil penelitian diperoleh data bahwa ada peningkatan kemampuan membaca peserta didik setelah menggunakan metode "suka uang" yaitu pada siklus 1 sebesar $62.36 \%$ dan pada siklus 2 sebesar $69.39 \%$.
\end{abstract}

Kata kunci: Pembelajaran membaca suku kata, Peserta didik Tunagrahita.

\section{PENDAHULUAN}

Tahap awal dari sebuah proses belajar membaca pada peserta didik sekolah dasar adalah membaca permulaan. Pada tahap ini peserta didik belajar memperoleh kemampuan membaca yang dimulai dari kemampuan menerjemahkan simbol atau gambar, huruf ke dalam suara yang dikombinasikan ke dalam suku kata, kata kemudian kalimat.

Menurut Sri Hedrawati (2010) metodemetode yang digunakan dalam pembelajaran membaca bervariasi diantaranya adalah metode eja, bunyi, suku kata, global, dan SAS (Struktur Analitik Sintetik).

Metode eja adalah belajar membaca yang dimulai dari mengeja huruf demi huruf. Pendekatan yang dipakai dalam metode eja adalah pendekatan harfiah, dimana peserta didik mulai diperkenalkan dengan lambang-lambang huruf. Pembelajaran metode eja terdiri dari pengenalan huruf atau abjad A sampai dengan $\mathrm{Z}$ dan pengenalan bunyi huruf atau fonem.

Metode bunyi sebagai metode pembelajaran membaca permulaan dengan menyuarakan konsonan, dengan bantuan vokal tengah (pepet), metode ini menurut Sri Hendrawati (2010) bisa dimasukan metode eja.

Selanjutnya metode kata lembaga, yang merupakan metode yang didasarkan atas pendekatan kata, yaitu cara memulai mengajarkan membaca dan menulis permulaan dengan menampilkan kata-kata. Kata-kata ini kemudian dibuat menjadi suku kata, kemudian diurai menjadi huruf.

Metode global atau metode kalimat merupakan metode belajar membaca kalimat secara utuh. Pembelajaran diawali dengan mengenalkan kalimat, kemudian kalimat diurai menjadi kata, suku kata, dan huruf. Dalam prakteknya, biasanya 
guru membantu dengan gambar-gambar. Adapun pendekatan yang dipakai dalam metode global ini adalah pendekatan kalimat.

Terakhir adalah metode SAS (Struktur Analitik Sintesis) yang merupakan salah satu metode untuk pembelajaran membaca dengan menampilkan sebuah kalimat utuh, pertama kalimat utuh itu diurai (Analitik) menjadi kata, suku kata sampai huruf. Setelah diurai huruf digabungkan kembali (Sintetik) menjadi suku kata, kata sehingga kembali disusun menjadi sebuah kalimat.

Semua metode tersebut bertujuan agar peserta didik memiliki kemampuan memahami dan menyuarakan tulisan dengan benar sebagai dasar ketrampilan membaca lanjut. Kemampuan membaca merupakan ketrampilan dasar bagi peserta didik sebagai bekal untuk dapat mengikuti pelajaran di sekolah. Dengan kemampuan membaca yang sudah dimiliki, peserta didik akan lebih mudah mengikuti kegiatan belajar mengajar.

Peserta didik tunagrahita menurut Dinie Ratri Desiningrum (2016: 16) adalah anak berkebutuhan khusus yang memiliki keterbelakangan dalam intelegensi, fisik, emosional dan sosial yang membutuhkan perlakuan khusus supaya dapat berkembang pada kemampuan yang maksimal.

Dinie Ratri Desiningrum (2016: mengkelompokkan peserta didik ini dalam tiga golongan yaitu mampu didik, mampu latih dan perlu rawat. Mampu didik merupakan mereka yang masih mempunyai kemampuan untuk dididik dalam bidang akademik yang sederhana (dasar) yaitu membaca, menulis dan berhitung. Mampu latih merupakan istilah yang dipakai untuk peserta didik yang secara fisik memiliki kelainan, baik sensori maupun motorisnya, sehingga hanya mampu dilatih kegiatan ADL (Activity of Daily Living) untuk menolong dirinya sendiri agar bisa hidup mandiri. Kelompok ketiga adalah anak mampu rawat, yaitu anak yang sepanjang hidupnya tergantung pada perawatan orang lain.

Menurut Rochyadi dan Alimin (2005) dalam Modul guru pembelajar SLB Tunagrahita (2016: 59) masalah yang dihadapi anak tunagrahita antara lain: masalah belajar, masalah penyesuian diri, masalah gangguan bicara dan bahasa, serta masalah kepribadian. Untuk peserta didik Tunagrahita mampu didik, meskipun dapat belajar akademik, mereka membutuhkan metode dan media yang diadaptasikan (adaptif) sehingga sesuai dengan karakteristiknya.

Media pembelajaran adaptif dalam Modul guru pembelajar SLB tunagrahita (2016: 32) diartikan sebagai media pembelajaran yang diadaptasikan sesuai dengan karakteristik masing-masing kelainan anak sehingga memenuhi kebutuhan pendidikan anak berkebutuhan khusus (ABK). Artinya media pembelajaran untuk $A B K$ harus disesuaikan dengan kondisi anak, dengan memperhatikan aspek-aspek pengembangan media antara lain: keberfungsian, kepraktisan, kemudahan, ketertarikan, keamanan dan efektifas. Jika pengembangan media sudah memenuhi aspek tersebut, diharapkan media pembelajaran akan benar-benar bermanfaat.

Menurut Kemp dan Deyton dalam modul guru pembelajar (2016: 35) ada beberapa manfaat media, yaitu: proses pembelajaran lebih jelas, menarik, interaktif, efisien waktu dan tenaga, meningkatkan kualitas proses dan hasil belajar, menumbuhkan sikap positif peserta didik dan media pembelajaran juga dapat mengubah peran guru sehingga lebih produktif.

Melihat pentingnya penggunaan media untuk mendapatkan hasil pembelajaran yang maksimal, maka diperlukan inovasi pembelajaran. Apalagi melihat hasil kegiatan belajar mengajar peserta didik kelas dua selama satu semester belum menunjukkan hasil yang memuaskan, dimana banyak anak belum dapat membaca, bahkan belum mengenal huruf sama sekali. Hal ini menuntut guru membuat media atau metode yang tepat, sebuah media yang mempertimbangkan karakteristik peserta didiknya dan mampu mengoptimalkan kemampuan anak.

Kembali pada kebutuhan peserta didik tunagrahita yang membutuhkan layanan pendidikan khusus yang disesuaikan dengan karakteristiknya, metode suku kata dianggap cukup tepat untuk pembelajaranmembacamereka. MenurutDepdikbud (1992:12) metode suku kata adalah suatu metode 
yang memulai pengajaran membaca permulaan dengan menyajikan kata-kata yang sudah di rangkai menjadi suku kata, kemudian suku-suku kata itu di rangkai menjadi kata yang terakhir merangkai kata menjadi kalimat.

Penelitan tindakan kelas ini menggunakan metode suku kata berulang yang diadaptasi sehingga mudah diucapkan oleh peserta didik tunagrahita. Penerapan metode ini juga diawali kegiatan ice breaker yang menyenangkan agar anak siap belajar. Metode pembelajaran suku kata berulang untuk selanjutnya peneliti menyebutnya "suka uang" tidak mengunakan urutan alphabet $(\mathrm{a}-\mathrm{z})$, akan tetapi menggunakan suku kata termudah yang dapat diucapkan peserta didik. Diharapkan setelah mengikuti ice breaker dan mengikuti kegiatan belajar mengajar dengan materi yang mudah, peserta didik akan termotivasi, muncul rasa percaya diri dan menyukai belajar, sehingga hasil pembelajaran akan meningkat.

\section{METODE PENELITIAN}

Penelitian ini merupakan penelitian tindakan kelas, yang dilaksanakan di kelas dengan tujuan memperbaiki dan meningkatkan kualitas pembelajaran.

Subyek dalam penelitian ini adalah peserta didik kelas dua SLB Manunggal Slawi, berjumlah 10 peserta didik terdiri atas 8 peserta didik laki-laki dan 2 peserta didik perempuan. Mereka adalah peserta didik mampu didik atau sering dikenal tunagrahita ringan yang masih mempunyai kemampuan untuk dididik dalam bidang akademik sederhana seperti membaca, menulis dan berhitung. Peserta didik ini memiliki intelegensi antara 55-70, sehingga sangat memungkinkan untuk diajar membaca.

Penelitian tindakan kelas dilaksanakan dalam 2 siklus, tiap siklus terdiri dari 3 pertemuan. Setiap pertemuan terdapat 4 kegiatan yang dilalui yaitu perencanaan, pelaksanaan, pengamatan (observasi), dan refleksi.

Tahap perencanaan meliputi : menyiapkan alat dan bahan, menyusun RPP, menyiapkan materi, menyusun lembar observasi dan menyiapakan instrument penilaian bagi peserta didik.
Tahap kedua adalah pelaksanaan, setiap peserta didik memiliki waktu 15 menit mengikuti kegiatan belajar mengajar. Pembelajaran dilaksanakan dengan model individual. Pada tahap ini kegiatan dirancang sebagai berikut :

\begin{tabular}{|c|l|c|}
\hline No & \multicolumn{1}{|c|}{ Kegiatan } & Waktu \\
\hline 1 & ice breaker & 5 menit \\
\hline 2 & Membaca & 10 menit \\
\hline
\end{tabular}

Materi diberikan berdasarkan tingkat kemudahan mengucapkan dari yang mudah ke tingkat yang sulit, materi siklus 1 yaitu :

\begin{tabular}{|c|c|l|}
\hline No & Kegiatan & \multicolumn{1}{c|}{ Materi } \\
\hline 1 & Pertemuan 1 & $\begin{array}{l}\text { ba }-\mathrm{bi}-\mathrm{bu}-\mathrm{be}-\mathrm{bo} \\
\mathrm{ma}-\mathrm{mi}-\mathrm{mu}-\mathrm{me}-\mathrm{mo} \\
\mathrm{pa}-\mathrm{pi}-\mathrm{pu}-\mathrm{pe}-\mathrm{po}\end{array}$ \\
\hline 2 & Pertemuan 2 & $\begin{array}{l}\mathrm{fa}-\mathrm{fi}-\mathrm{fu}-\mathrm{fe}-\mathrm{fo} \\
\mathrm{va}-\mathrm{va}-\mathrm{va}-\mathrm{va}-\mathrm{va} \\
\mathrm{wa}-\mathrm{wi}-\mathrm{wu}-\mathrm{we}-\mathrm{wo}\end{array}$ \\
\hline 3 & Pertemuan 3 & $\begin{array}{l}\text { ta }-\mathrm{ti}-\mathrm{tu}-\mathrm{te}-\mathrm{to} \\
\mathrm{ja}-\mathrm{ji}-\mathrm{ju}-\mathrm{je}-\mathrm{jo} \\
\mathrm{ya}-\mathrm{yi}-\mathrm{yu}-\mathrm{ye}-\mathrm{yo}\end{array}$ \\
\hline
\end{tabular}

Materi siklus 2 :

\begin{tabular}{|c|c|l|}
\hline No & Kegiatan & \multicolumn{1}{c|}{ Materi } \\
\hline 1 & Pertemuan 1 & $\begin{array}{l}\mathrm{da}-\mathrm{di}-\mathrm{du}-\mathrm{de}-\mathrm{do} \\
\mathrm{na}-\mathrm{ni}-\mathrm{nu}-\mathrm{ne}-\mathrm{no} \\
\mathrm{ra}-\mathrm{ri}-\mathrm{ru}-\mathrm{re}-\mathrm{ro}\end{array}$ \\
\hline 2 & Pertemuan 2 & $\begin{array}{l}\mathrm{ca}-\mathrm{ci}-\mathrm{cu}-\mathrm{ce}-\mathrm{co} \\
\mathrm{ha}-\mathrm{hi}-\mathrm{hu}-\mathrm{he}-\mathrm{ho} \\
\mathrm{sa}-\mathrm{si}-\mathrm{su}-\mathrm{se}-\mathrm{so}\end{array}$ \\
\hline 3 & Pertemuan 3 & $\begin{array}{l}\mathrm{za}-\mathrm{zi}-\mathrm{zu}-\mathrm{ze}-\mathrm{zo} \\
\mathrm{ka}-\mathrm{ki}-\mathrm{ku}-\mathrm{ke}-\mathrm{ko} \\
\mathrm{ga}-\mathrm{gi}-\mathrm{gu}-\mathrm{ge}-\mathrm{go}\end{array}$ \\
\hline
\end{tabular}

Tahap ketiga merupakan kegiatan pengamatan (observasi) yang dilakukan peneliti dan kolaborator. Peneliti mengamati kegiataan peserta didik pada saat belajar sekaligus mengamati hasil kegiatan membaca seperti : keluarnya bunyi, getaran organ bicara maupun sikap peserta didik.

Tahap keempat adalah refleksi, dimana peneliti memeriksa, menganalisis serta mendiskusikan hasil analisis untuk tindakan perbaikan pada pelaksanaan kegiatan belajar berikutnya. 
Jenis data yang digunakan dalam penelitian ini adalah data kualitatif dan kuantitatif yang terdiri dari: data kemampuan membaca peserta didik, data pelaksanaan pembelajaran, data evaluasi hasil belajar peserta didik.

Teknik pengumpulan data yang digunakan dengan metode observasi dan metode dokumentasi, sedangkan data yang diperoleh pada penelitian ini adalah data kualilatif dan kuantitatif. Data kuantitatif diperolehdari skor pre-tes dan post-tes, sedang data kualitatif diperoleh dari observasi dan dokumentasi. Hasil Observasi dari kolaborator di olah untuk dihitung rata-ratanya, yaitu: Sangat Baik (SB) skor 4, Baik (B) skor 3, Kurang Baik (BK) skor 2, dan Sangat Kurang (SK) diberi skor 1. Selanjutnya Hasil Observasi di oleh secara deskriptif.

\section{HASIL DAN PEMBAHASAN}

Penelitian ini diadakan di SLB Manunggal Slawi pada peserta didik tunagrahita kelas dua semester dua tahun pembelajaran 2019/2020 tepatnya pada bulan Januari sampai dengan Maret.

Pembalajaran membaca yang penulis lakukan masih menggunakan metode eja, yaitu memperkenalkan huruf demi huruf untuk dirangkai menjadi kata. Pada metode ini penulis membuat kartu huruf $\mathrm{A}-\mathrm{Z}$, dan mengajarkan pada peserta didik. Peserta didik terlihat kesulitan mengucapkan huruf, apalagi merangkainya menjadi kata. Hasil pembelajaran membaca menggunakan metode eja dapat dilihat pada tabel dibawah ini.

Tabel 1. Pra Siklus : Hasil Pembelajaran Membaca Menggunakan Metode Eja Semester I Tahun Pelajaran 2019/2020

\begin{tabular}{|c|l|c|c|c|c|c|c|c|c|c|c|c|}
\hline No & Nama & $\mathrm{a}$ & $\mathrm{b}$ & $\mathrm{c}$ & $\mathrm{d}$ & $\mathrm{e}$ & $\mathrm{f}$ & $\mathrm{g}$ & $\mathrm{h}$ & $\mathrm{i}$ & $\mathrm{J}$ & Nilai \\
\hline 1 & $\mathrm{Ah}$ & $\mathrm{X}$ & $\mathrm{X}$ & $\mathrm{X}$ & $\mathrm{X}$ & $\mathrm{X}$ & $\mathrm{X}$ & $\mathrm{X}$ & $\mathrm{X}$ & $\mathrm{X}$ & $\mathrm{X}$ & 0 \\
\hline 2 & $\mathrm{Al}$ & $\mathrm{V}$ & $\mathrm{V}$ & $\mathrm{X}$ & $\mathrm{X}$ & $\mathrm{X}$ & $\mathrm{X}$ & $\mathrm{X}$ & $\mathrm{X}$ & $\mathrm{V}$ & $\mathrm{X}$ & 30 \\
\hline 3 & $\mathrm{Fa}$ & $\mathrm{X}$ & $\mathrm{X}$ & $\mathrm{X}$ & $\mathrm{X}$ & $\mathrm{X}$ & $\mathrm{X}$ & $\mathrm{X}$ & $\mathrm{X}$ & $\mathrm{X}$ & $\mathrm{X}$ & 0 \\
\hline 4 & $\mathrm{Gh}$ & $\mathrm{X}$ & $\mathrm{X}$ & $\mathrm{X}$ & $\mathrm{X}$ & $\mathrm{X}$ & $\mathrm{X}$ & $\mathrm{X}$ & $\mathrm{X}$ & $\mathrm{X}$ & $\mathrm{X}$ & 0 \\
\hline 5 & $\mathrm{Hi}$ & $\mathrm{X}$ & $\mathrm{X}$ & $\mathrm{X}$ & $\mathrm{X}$ & $\mathrm{X}$ & $\mathrm{X}$ & $\mathrm{X}$ & $\mathrm{X}$ & $\mathrm{X}$ & $\mathrm{X}$ & 0 \\
\hline 6 & $\mathrm{Nab}$ & $\mathrm{X}$ & $\mathrm{X}$ & $\mathrm{X}$ & $\mathrm{X}$ & $\mathrm{X}$ & $\mathrm{X}$ & $\mathrm{X}$ & $\mathrm{X}$ & $\mathrm{X}$ & $\mathrm{X}$ & 0 \\
\hline 7 & $\mathrm{Naf}$ & $\mathrm{X}$ & $\mathrm{X}$ & $\mathrm{X}$ & $\mathrm{X}$ & $\mathrm{X}$ & $\mathrm{X}$ & $\mathrm{X}$ & $\mathrm{X}$ & $\mathrm{X}$ & $\mathrm{X}$ & 0 \\
\hline 8 & $\mathrm{Ra}$ & $\mathrm{V}$ & $\mathrm{V}$ & $\mathrm{X}$ & $\mathrm{X}$ & $\mathrm{X}$ & $\mathrm{X}$ & $\mathrm{X}$ & $\mathrm{V}$ & $\mathrm{V}$ & $\mathrm{X}$ & 40 \\
\hline 9 & $\mathrm{Sa}$ & $\mathrm{X}$ & $\mathrm{X}$ & $\mathrm{X}$ & $\mathrm{X}$ & $\mathrm{X}$ & $\mathrm{X}$ & $\mathrm{X}$ & $\mathrm{X}$ & $\mathrm{X}$ & $\mathrm{X}$ & 0 \\
\hline 10 & $\mathrm{Ul}$ & $\mathrm{X}$ & $\mathrm{X}$ & $\mathrm{X}$ & $\mathrm{X}$ & $\mathrm{X}$ & $\mathrm{X}$ & $\mathrm{X}$ & $\mathrm{X}$ & $\mathrm{X}$ & $\mathrm{X}$ & 0 \\
\hline
\end{tabular}

Keterangan : Tanda silang (X) menunjukkan peserta didik belum dapat mengikuti perintah.

Tanda centang (V) menunjukkan peserta didik sudah dapat mengikuti perintah

Dari tabel diatas terlihat bahwa sebagian besar peserta didik kelas dua tahun pelajaran 2019/ 2020 kemampuan membacanya masih sangat rendah. Hal ini disebabkan para peserta didik mengalami kesulitan mengucapkan b, c, d, f. dan hurup selanjutnya.

Melihat hasil pembelajaran yang kurang memuaskan, peneliti memilih metode pembelajaran suku kata berulang dengan pertimbangan, peserta didik lebih mudah mengucapkan kata ba, bi, bu, be, bo dibandingkan hurup $\mathrm{b}$ dan $\mathrm{i}, \mathrm{b}$ dan $\mathrm{u}$, atau selanjutnya.
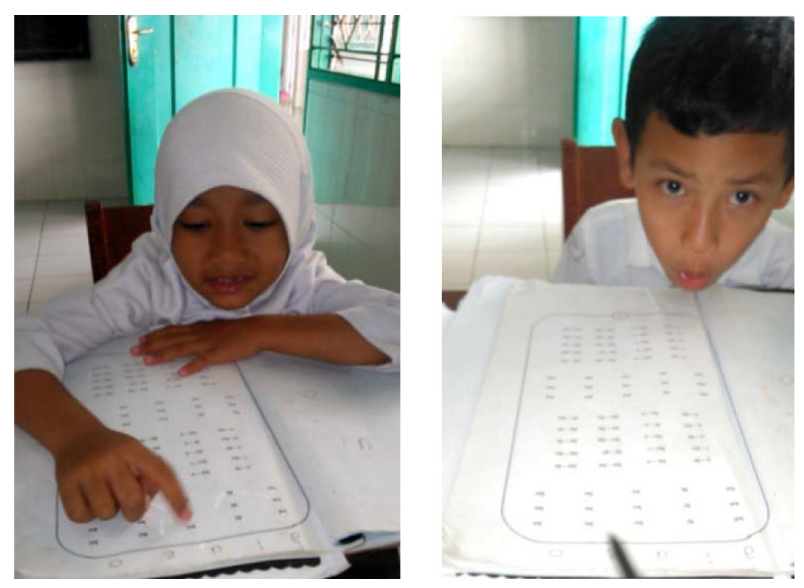

Gambar 2. Foto Kegiatan Pelaksanaan Siklus 1 
Tabel 2 : Hasil pembelajaran membaca pada siklus 1 pertemuan 1

\begin{tabular}{|c|l|c|c|c|c|}
\hline \multirow{2}{*}{ No } & \multirow{2}{*}{ Nama } & \multicolumn{3}{|c|}{ Materi } & \multirow{2}{*}{ Nilai } \\
\cline { 3 - 5 } & & ba, bi, bu, be, bo & ma, mi, mu, me, mo & pa, pi, pu, pe, po & \\
\hline 1 & $\mathrm{Ah}$ & $\mathrm{V}$ & $\mathrm{X}$ & $\mathrm{X}$ & 33,33 \\
\hline 2 & $\mathrm{Al}$ & $\mathrm{V}$ & $\mathrm{V}$ & $\mathrm{V}$ & 100 \\
\hline 3 & $\mathrm{Fa}$ & $\mathrm{V}$ & $\mathrm{V}$ & $\mathrm{X}$ & 66,66 \\
\hline 4 & $\mathrm{Gh}$ & $\mathrm{V}$ & $\mathrm{V}$ & $\mathrm{X}$ & 66,66 \\
\hline 5 & $\mathrm{Hi}$ & $\mathrm{V}$ & $\mathrm{X}$ & $\mathrm{V}$ & 33,33 \\
\hline 6 & $\mathrm{Nab}$ & $\mathrm{V}$ & $\mathrm{V}$ & $\mathrm{V}$ & 100 \\
\hline 7 & $\mathrm{Naf}$ & $\mathrm{V}$ & $\mathrm{V}$ & $\mathrm{V}$ & 100 \\
\hline 8 & $\mathrm{Ra}$ & $\mathrm{V}$ & $\mathrm{X}$ & $\mathrm{X}$ & 33,33 \\
\hline 9 & $\mathrm{Sa}$ & $\mathrm{V}$ & $\mathrm{V}$ & $\mathrm{V}$ & 100 \\
\hline 10 & $\mathrm{Ul}$ & $\mathrm{V}$ & & & \\
\hline
\end{tabular}

Tabel 3 : Hasil pembelajaran membaca pada siklus 1 pertemuan 2

\begin{tabular}{|c|l|c|c|c|c|}
\hline \multirow{2}{*}{ No } & \multirow{2}{*}{ Nama } & \multicolumn{3}{|c|}{ Materi } & \multirow{2}{*}{ Nilai } \\
\cline { 3 - 5 } & & fa, fi, fu, fe, fo & va, vi, vu, ve, vo & wa, wi, wu, we, wo & \\
\hline 1 & $\mathrm{Ah}$ & $\mathrm{V}$ & $\mathrm{x}$ & $\mathrm{V}$ & 66,66 \\
\hline 2 & $\mathrm{Al}$ & $\mathrm{V}$ & $\mathrm{v}$ & $\mathrm{V}$ & 100 \\
\hline 3 & $\mathrm{Fa}$ & $\mathrm{V}$ & $\mathrm{v}$ & $\mathrm{V}$ & 100 \\
\hline 4 & $\mathrm{Gh}$ & $\mathrm{V}$ & $\mathrm{v}$ & $\mathrm{V}$ & 66,66 \\
\hline 5 & $\mathrm{Hi}$ & $\mathrm{V}$ & $\mathrm{x}$ & $\mathrm{V}$ & 100 \\
\hline 6 & $\mathrm{Nab}$ & $\mathrm{V}$ & $\mathrm{v}$ & $\mathrm{V}$ & 100 \\
\hline 7 & $\mathrm{Naf}$ & $\mathrm{V}$ & $\mathrm{v}$ & $\mathrm{V}$ & 100 \\
\hline 8 & $\mathrm{Ra}$ & $\mathrm{V}$ & $\mathrm{x}$ & $\mathrm{V}$ & 66,66 \\
\hline 9 & $\mathrm{Sa}$ & $\mathrm{V}$ & $\mathrm{v}$ & $\mathrm{V}$ & 100 \\
\hline 10 & $\mathrm{Ul}$ & $\mathrm{V}$ & & & \\
\hline
\end{tabular}

Tabel 4 : Hasil pembelajaran membaca pada siklus 1 pertemuan 3.

\begin{tabular}{|c|l|c|c|c|c|}
\hline \multirow{2}{*}{ No } & \multirow{2}{*}{ Nama } & \multicolumn{3}{|c|}{ Materi } & \multirow{2}{*}{ Nilai } \\
\cline { 3 - 5 } & & ta, ti, tu, te, to & ja, ji, ju, je, jo & ya, yi, yu, ye, yo & 100 \\
\hline 1 & $\mathrm{Ah}$ & $\mathrm{V}$ & $\mathrm{v}$ & $\mathrm{V}$ & 100 \\
\hline 2 & $\mathrm{Al}$ & $\mathrm{V}$ & $\mathrm{V}$ & $\mathrm{V}$ & 100 \\
\hline 3 & $\mathrm{Fa}$ & $\mathrm{V}$ & $\mathrm{v}$ & $\mathrm{V}$ & 100 \\
\hline 4 & $\mathrm{Gh}$ & $\mathrm{V}$ & $\mathrm{v}$ & $\mathrm{V}$ & 66,66 \\
\hline 5 & $\mathrm{Hi}$ & $\mathrm{V}$ & $\mathrm{x}$ & $\mathrm{V}$ & 100 \\
\hline 6 & $\mathrm{Nab}$ & $\mathrm{V}$ & $\mathrm{v}$ & $\mathrm{V}$ & 100 \\
\hline 7 & $\mathrm{Naf}$ & $\mathrm{V}$ & $\mathrm{V}$ & $\mathrm{V}$ & 100 \\
\hline 8 & $\mathrm{Ra}$ & $\mathrm{V}$ & $\mathrm{x}$ & $\mathrm{V}$ & 66,66 \\
\hline 9 & $\mathrm{Sa}$ & $\mathrm{V}$ & $\mathrm{v}$ & $\mathrm{V}$ & 100 \\
\hline 10 & $\mathrm{Ul}$ & $\mathrm{V}$ & & & \\
\hline
\end{tabular}


Tabel 5. Perbandingan hasil pembelajaran membaca Siklus 1.

\begin{tabular}{|c|c|c|c|c|c|c|}
\hline \multirow{2}{*}{ No } & \multirow{2}{*}{ Nama } & \multicolumn{4}{|c|}{ Nilai } & \multirow{2}{*}{ Rata-rata } \\
\hline & & Pra Siklus & Pertemuan 1 & Pertemuan 2 & Pertemuan 3 & \\
\hline 1 & $\mathrm{Ah}$ & 0 & 33,33 & 66,66 & 100 & 66,66 \\
\hline 2 & $\mathrm{Al}$ & 30 & 100 & 100 & 100 & 100 \\
\hline 3 & $\mathrm{Fa}$ & 0 & 66,66 & 100 & 100 & 88,89 \\
\hline 4 & Gh & 0 & 66,66 & 100 & 100 & 88,89 \\
\hline 5 & $\mathrm{Hi}$ & 0 & 33,33 & 66.66 & 66.66 & 55,55 \\
\hline 6 & $\mathrm{Nab}$ & 0 & 100 & 100 & 100 & 100 \\
\hline 7 & $\mathrm{Naf}$ & 0 & 100 & 100 & 100 & 100 \\
\hline 8 & $\mathrm{Ra}$ & 40 & 100 & 100 & 100 & 100 \\
\hline 9 & $\mathrm{Sa}$ & 0 & 33,33 & 66,66 & 66,66 & 55,55 \\
\hline 10 & Ul & 0 & 100 & 100 & 100 & 100 \\
\hline
\end{tabular}

Pelaksanaan pembelajaran membaca "suka uang" siklus 1 berdasarkan hasil pengamatan kolaborator sangat positif, hal ini bisa dilihat pada rata-rata hasil pembelajaran pada tabel 1 . Metode pembelajaran ini mudah diikuti peserta didik, mereka dapat mengucapkan suku kata yang diajarkan guru. Selain mudah diikuti, penggunaan ice breaker yang menyenangkan dapat membangkitkan minat peserta didik dalam belajar membaca, sekaligus mempertahankan berkonsentrasi peserta didik dalam waktu cukup lama.

Berikut adalah grafik hasil analisis nilai peningkatan kemampuan membaca peserta didik Tunagrahita kelas dua SLB Manunggal tahun pelajaran 2019/2020

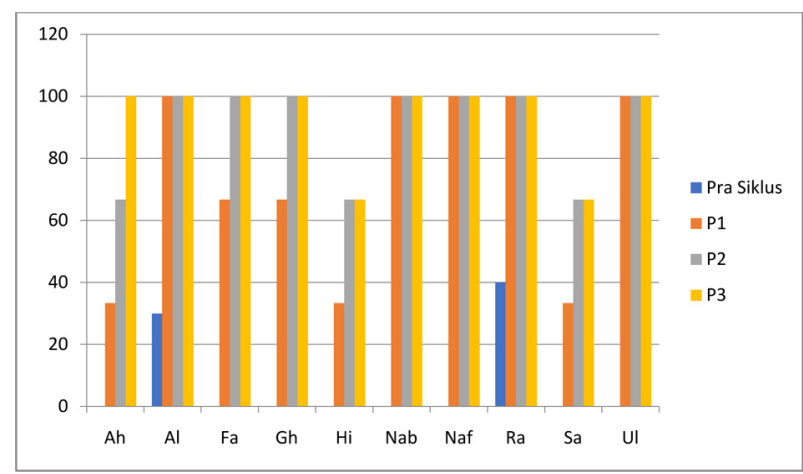

Grafik 1. Hasil Pembelajaran Membaca siklus 1

Berdasarkan hasil refleksi di akhir pertemuan 1, 2 dan 3 siklus 1 diperoleh data bahwa kemampuan membaca berdasarkan N-gain di akhir siklus 1 sebesar 62.36, artinya terdapat peningkatan sebesar 46,11 dari kondisi awal 16,25 atau terjadi peningkatan kemampuan membaca sebesar 62.36 $\%$.

Hasil pembelajaran membaca "suka uang" pada siklus 1 menunjukkan adanya perubahan kemampuan membaca yang cukup baik, hal ini disebabkan antusias peserta didik yang meningkat. Peserta didik melakukan ice breaker dengan senang dan semangat. Mereka juga menunjukan kemauan yang tinggi untuk dapat mengucapkan suku kata yang diperintah.

Tindakan pada siklus 2 dibuat dalam 3 pertemuan, dimana setiap peserta didik mempunyai waktu 15 menit melakukan pembelajaran membaca. Langkah pembelajaran sama dengan pembelajaran pada siklus 1 .

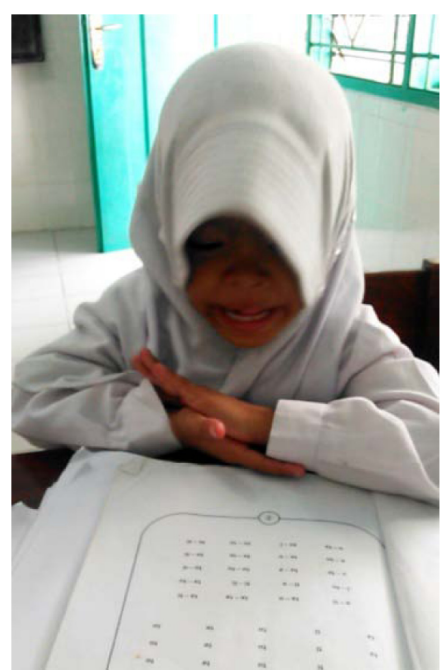

Gambar 2. Foto Kegiatan Pelaksanaan Siklus 2 
Tabel 6. Hasil pembelajaran membaca Siklus 2

\begin{tabular}{|c|l|c|c|c|c|}
\hline \multirow{2}{*}{ No } & \multirow{2}{*}{ Nama } & \multicolumn{3}{|c|}{ Nilai } & \multirow{2}{*}{ Rata-rata } \\
\cline { 3 - 5 } & & Pertemuan 1 & Pertemuan 2 & Pertemuan 3 & \\
\hline 1 & $\mathrm{Ah}$ & 100 & 100 & 100 & 100 \\
\hline 2 & $\mathrm{Al}$ & 100 & 100 & 100 & 100 \\
\hline 3 & $\mathrm{Fa}$ & 66,66 & 100 & 100 & 88,89 \\
\hline 4 & $\mathrm{Gh}$ & 66,66 & 100 & 100 & 88,89 \\
\hline 5 & $\mathrm{Hi}$ & 66,66 & 100 & 100 & 88,89 \\
\hline 6 & $\mathrm{Nab}$ & 100 & 100 & 100 & 100 \\
\hline 7 & $\mathrm{Naf}$ & 100 & 100 & 100 & 100 \\
\hline 8 & $\mathrm{Ra}$ & 100 & 100 & 100 & 100 \\
\hline 9 & $\mathrm{Sa}$ & 100 & 100 & 100 & 100 \\
\hline 10 & $\mathrm{Ul}$ & 100 & 100 & 100 & 100 \\
\hline
\end{tabular}

Hasil Refleksi di akhir pertemuan 1, 2 dan 3 pada siklus 2 adalah terjadi peningkatan kemampuan membaca berdasarkan $\mathrm{N}$-gain sebesar 69.39, artinya terdapat peningkatan sebesar 53,14 dari kondisi awal 16,25 atau terjadi peningkatan kemampuan membaca sebesar $69.39 \%$.

Berikut adalah grafik hasil analisis nilai peningkatan kemampuan membaca peserta didik Tunagrahita kelas II SLB Manunggal tahun pelajaran 2019/2020.

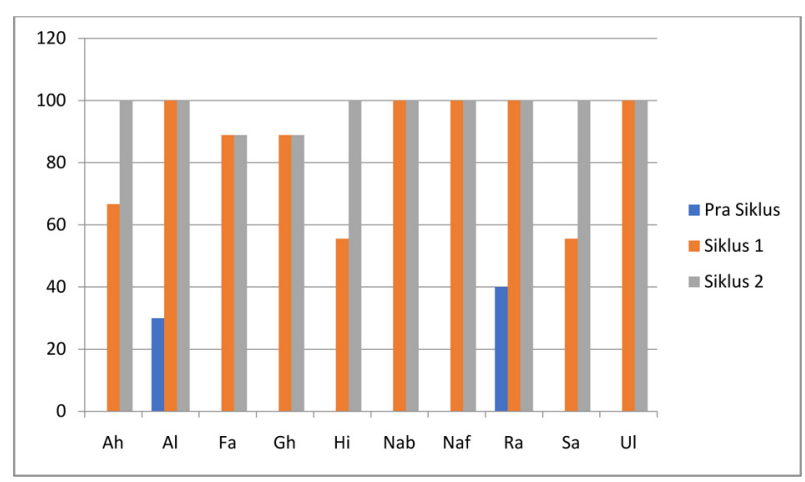

Grafik 2. Nilai Peningkatan Hasil Pembelajaran Membaca Peserta Didik Tunarungu Kelas I SLB Manunggal Slawi

Berdasarkan hasil analisis data diperoleh gambaran adanya peningkatan kemampuan membaca pada siklus 1 sebesar $62.36 \%$ dan pada siklus 2 sebesar $69.39 \%$. Peningkatan kemampuan ini disebabkan peserta didik semangat mengikuti kegiatan belajar mengajar dan konsentrasi, ice breaker diawal pelajaran menumbuhkan rasa senang. Peserta didik mau mengikuti instruksi guru untuk mengucapkan suku kata berulang dengan semangat, kondisi ini menyebabkan kegiatan belajar mengajar menjadi maksimal.

Peningkatan pada tiap peserta didik memang berbeda, hal ini dimungkinkan karena beberapa factor, seperti : intelegensi dan karakter social peserta didik. Keterbatasan intelegensi menyebabkan daya tangkap anak terbatas, metode suku kata menyederhanakan kerja otak, anak cukup mengingat "ba" bukan b dan a. Selain itu juga metode berulang dapat menjawab permasalahan anak tunagrahita yang sulit menerima materi, sehingga membutuhkan pengulangan.

\section{SIMPULAN}

Berdasarkan hasil Penelitian tindakan kelas yang sudah dilakukan pada peserta didik tunagrahita kelas dua SLB Manunggal Slawi Semester dua tahun pelajaran 2019/2020, dapat disimpulkan ada peningkatan kemampuan membaca pada siklus 1 sebesar $62.36 \%$ dan pada siklus 2 sebesar $69.39 \%$, Artinya ada kenaikan kemampuan membaca lebih dari $60 \%$ sehingga pembelajaran membaca "suka uang" dinyatakan berhasil.

\section{DAFTAR PUSTAKA}

Fatimah, Enung. (2006) Psikologi Perkembangan (Perkembangan Peserta Didik), Bandung, Pustaka Setia.

Hendrawati, Sri. (2010) Metode-metode pembelajaran Menulis Permulaan (MMP) di sekolah dasar 
Rusman. (2012). Belajar dan Pembelajaran Berbasis Komputer. Bandung: Alfabeta

Haryono. (2015). Penelitian Tindakan Kelas (PTK).

Yogyakarta: Amara Books

Ratri Desiningrum, Dinie. (2016) Psikologi Anak

Berkebutuhan Khusus, Yogyakarta,

Psikosain

Modul Guru Pembelajar SLB Tunagrahita. (2016)

Bandung, PPPTK TK dan PLB Bandung.

Subyantoro. (2017) Penelitian Tindakan Kelas

(Edisi 5), Semarang, Farishma Indonesia. 